\title{
Inadvertent doping through nutritional supplements is a reality
}

\author{
$P$ J van der Merwe (PhD) \\ E Grobbelaar (MSc Chem) \\ South African Doping Control Laboratory, Department of Pharmacology, University of the Free State, Bloemfontein
}

\begin{abstract}
Objective. Inadvertent doping through the use of nutritional supplements is a potentially important cause of the increase in positive drug tests involving high-profile Olympic athletes. The aim of this study was to screen over-the-counter nutritional supplements for the presence of steroid or stimulant compounds banned by the International Olympic Committee (IOC) and the World Anti-Doping Agency (WADA).

Method. Thirty different nutritional supplements from 14 different manufacturers were bought at shops in Bloemfontein, South Africa and analysed for testosterone and nandrolone prohormones, various ephedrines and caffeine.

Results. Eighteen (60\%) of the 30 supplements contained no prohibited substances. Of the $12(40 \%)$ positive supplements, $8(66.7 \%)$ contained prohormones and 4 (33.3\%) contained stimulants. Six supplements contained prohormones, which were listed on the labels, while 2 contained prohormones not listed on the labels. The stimulants were listed on the labels as Ma Huang, Guarana and Kola extracts and all contained a mixture of ephedrines and caffeine.

Conclusion. The results showed that approximately $7 \%$ of supplements tested may be mislabelled or contaminated with banned substances and that inadvertent doping through nutritional supplement use is a reality for athletes. The sporting community should therefore be aware that supplements might contain anabolic androgenic steroids and stimulants that are not declared on the labels.
\end{abstract}

\section{CORRESPONDENCE:}

\section{P J van der Merwe}

South African Doping Control Laboratory

Department of Pharmacology

University of the Free State

PO Box 339

Bloemfontein

9300

Tel: 051-4013182

Fax: 051-444 1523

E-mail: gnfmpvdm.md@mail.uovs.ac.za

\section{Introduction}

In 1994 legislation was passed by the United States Food and Drug Administration (FDA) in which the government control of supplement production was relaxed. This Dietary Supplement and Health Education Act resulted in several androgenic steroids, e.g. androstenedione and dehydroepiandrosterone (DHEA) becoming legal and available for purchase over the counter without a prescription. This sudden growth of dietary supplement production has led to some questionable quality control manufacturing practices, resulting in contamination of nutritional supplements, which may be a possible explanation for the apparent increase in the number of positive doping tests amongst high profile athletes. Nutritional supplement use is also very popular in South Africa and the turnover of the industry is approximately R1.5 billion a year (Health Products Association of South Africa Survey 1998 - 2000).

Nutritional supplements include vitamins, minerals, herbal powders, carbohydrates and protein powders. Vitamins and minerals are not prohibited substances in sport, but may be combined with substances that are prohibited. There are a wide variety of nutritional substances specifically designed for athletes. Athletes assume that these supplements do not contain prohibited substances because they are readily available without prescriptions and are sold legally as supplements. The reasons why athletes use supplements include performance enhancement, faster recovery during training, manipulation of body composition and reduction in illness or infection risks (Maughan R. The scope of nutritional supplement use in sport. Health and Doping Risks of Nutritional Supplements and Social Drugs. Cologne, Germany: International Symposium, 18 July 2002.)

Recent studies have shown that non-hormonal nutritional supplements such as vitamins, minerals and amino acids may contain banned substances not listed on the label. ${ }^{4}$ Results from an International Olympic Committee (IOC) study $^{5}$ on nutritional supplements (13 countries excluding South Africa) showed that 94 (14.8\%) of 634 samples contained prohormones not listed on the label. Both Catlin et al. ${ }^{1}$ and Kamber et al. ${ }^{6}$ analysed nutritional supplements and found hormone contaminants not listed on the labels. This may explain the recent increase in positive doping cases. Nutritional supplement manufacturing is not subject to the same stringent regulatory inspection and licensing requirements as is the case with medicines (Schröder $U$. 
Health effects of nutritional supplements. Health and Doping Risks of Nutritional Supplements and Social Drugs. Cologne, Germany: International Symposium, 18 July 2002.) The result is inaccurate product labelling, batch composition differences and possible contamination with prohormones, which are prohibited substances in sport.

\section{Objective}

The aim of this study was to screen over-the-counter nutritional supplements for steroids (testosterone, nandrolone and prohormones) and stimulant compounds in an attempt to define the extent of supplement contamination or mislabelling.

\section{Method}

Thirty different nutritional supplements from 14 different manufacturers were bought at random at shops in Bloemfontein and analysed for testosterone, nandrolone, their prohormones, various ephedrines and caffeine.

The prohormones were extracted as follows. Approximately $1 \mathrm{~g}$ of supplement was extracted with $5 \mathrm{ml}$ methanol. The methanolic layer was evaporated and made basic with $5 \mathrm{ml}$ potassium hydroxide $(0.1 \mathrm{M}, \mathrm{pH}>12)$. Re-extraction with $5 \mathrm{ml} \mathrm{n}$-pentane was followed by another methanol extraction, which was evaporated. Derivatisation with 80 $\mu \mathrm{l} \mathrm{MSTFA} / \mathrm{NH}_{4} / /$ ethanethiol $(1000: 2: 3 \mathrm{v} / \mathrm{w} / \mathrm{v})$ for 30 minutes at $60^{\circ} \mathrm{C}$ followed. The sample was diluted with $140 \mu$ toluene and analysed using an Agilent (Palo Alto, CA, USA) gas chromatograph $(6890 \mathrm{~N}$ series) interfaced with a mass selective detector ( $5973 \mathrm{~N}$ series).

The quantity of DHEA, 4-androstenedione and 19-nor-4androstenedione for supplements 19 and 20 were deter- mined by analysing 5 capsules from each container.

The ephedrines ${ }^{8}$ and caffeine ${ }^{2}$ in the samples were extracted and quantified according to standard laboratory procedures.

\section{Results}

Eighteen (60\%) of the 30 supplements contained no prohibited substances. Of the $12(40 \%)$ positive supplements, 8 $(66.7 \%)$ contained prohormones and $4(33.3 \%)$ contained stimulants. Two $(6.7 \%)$ of the supplements were contaminated or mislabelled. The prohormones and stimulants found in the nutritional supplements are listed in Tables I and II, respectively. Stimulants were only listed as herbal extracts as indicated in Table II.

Four supplements $(6,7,14$ and 24$)$ contained the prohormone DHEA which was listed on the label in each case. Supplement 22 contained DHEA and 4-androstenedione with both substances listed on the label. Supplement 5 contained the banned substance 19-nor-4-androstenedione, which was listed on the label. Supplement 19 only listed branched chain amino acids on the label but small amounts of DHEA and 4-androstenedione were found in the capsules. No indication of the presence of these two compounds could be found on the label. Supplement 20 had $\beta$-hydroxy$\beta$-methylbuturate (HMB) listed on the label but small amounts of 4-androstenedione and 19-nor-4-androstenedione (both substances not listed on the label) were found. A second container of supplement 19 (19B) and supplement 20 (20B) were obtained from the same shop and analysed. Supplement 19B also tested positive for DHEA and 4androstenedione but in different quantities than in 19A. No 4androstenedione or 19-nor-4-androstenedione was detected in the 20B.

\begin{tabular}{|c|c|c|c|}
\hline $\begin{array}{l}\text { Supplement } \\
\text { no }\end{array}$ & Listed on label & Found & $\begin{array}{l}\mu g / c a p s u l e \\
\text { Mean (range) }\end{array}$ \\
\hline 5 & 19-nor-4-androstenedione & 19-nor-4-androstenedione & \\
\hline \multirow[t]{2}{*}{6} & DHEA & DHEA & \\
\hline & Pregnenolone & & \\
\hline 7 & DHEA & DHEA & \\
\hline 14 & DHEA & DHEA & \\
\hline \multirow[t]{2}{*}{$19 A^{*}$} & Branched-chain amino acids & DHEA & $0.76(0.67-0.85)$ \\
\hline & & 4-androstenedione & $1.64(1.35-1.94)$ \\
\hline \multirow[t]{2}{*}{$19 B^{*}$} & Branched-chain amino acids & DHEA & $14.00(7.40-17.80)$ \\
\hline & & 4-androstenedione & $8.21(4.10-12.90)$ \\
\hline \multirow[t]{2}{*}{$20 A^{*}$} & HMB & 4-androstenedione & $0.16(0.10-0.35)$ \\
\hline & & 19-nor-4-androstenedione & $16.5(8.40-31.80)$ \\
\hline $20 B^{*}$ & HMB & No banned substance & \\
\hline \multirow[t]{3}{*}{22} & DHEA & DHEA & \\
\hline & 4-androstenedione & 4-androstenedione & \\
\hline & Tribulus Terristris & & \\
\hline 24 & DHEA & DHEA & \\
\hline $\begin{array}{l}\text { *Five capsules pe } \\
\text { DHEA = dehydro }\end{array}$ & $\begin{array}{l}\text { ere analysed. } \\
\text { ne; } \mathrm{HMB}=\beta \text {-hydroxy } \beta \text {-methylbutyrate }\end{array}$ & & \\
\hline
\end{tabular}




\section{TABLE II. Stimulants found in nutritional supplements}

Supplement Listed on label Found $\mathrm{mg} /$ capsule

$\begin{array}{llr}\text { Gotu kola } & \text { Caffeine } & 30.0 \\ \text { Herbal tea blend } & \text { Ephedrine } & 7.3 \\ & \text { Pseudoephedrine } & 1.1 \\ & \text { Methylephedrine } & 0.3\end{array}$

3

Kola extract Caffeine

Ma Huang extract Ephedrine $\quad 1.5$

Pseudoephedrine $\quad 2.4$

Methylephedrine $\quad 6.8$

$18 \quad$ Guarana extract Caffeine 39.0

Ma Huang extract Ephedrine $\quad 3.2$

Pseudoephedrine $\quad 0.3$

Methylephedrine $\quad 0.1$

21

$\begin{array}{llr}\text { Guarana extract } & \text { Caffeine } & 63.7 \\ \text { Ma Huang extract } & \text { Ephedrine } & 6.6 \\ & \text { Pseudoephedrine } & 0.9 \\ & \text { Methylephedrine } & 0.3\end{array}$

\section{Discussion}

Six supplements contained prohormones of testosterone (DHEA and 4-androstenedione) and nandrolone (19-nor-4androstenedione) as listed on the labels. Careful reading of the label and obtaining information on whether the supplement is on the banned list of the IOC/World Anti-Doping Agency (WADA), should alert the athlete to avoid these supplements and therefore reduce the chances of a positive dope test. The problem lies with supplements where there is no indication on the label that they contain banned substances. Supplement 19 listed branched chain amino acids on the label, with no indication that it contained banned substances. Yet when the capsules were tested, low amounts of DHEA and 4-androstenedione were found. Supplement 20 listed HMB on the label, but when it was tested low amounts of 4-androstenedione and 19-nor-4-androstenedione were found. Kamber et al. ${ }^{6}$ analysed 75 different nutritional supplements and found that more than $9 \%$ contained hormonal substances not listed on the labels, a finding similar to this study.

There was a significant difference in the quantity of DHEA and 4-androstenedione found in the two supplement containers 19A and 19B (18-fold for DHEA and 5-fold for 4androstenedione). There was also a wide range of concentration in individual capsules of the 2 supplement products (especially in container 19B). The same applies for the quantity of 4-androstenedione and 19-nor-4-androstenedione in supplement 20A. This clearly shows that there was no quality control in the manufacturing process of supplements 19 and 20. Catlin et al. ${ }^{1}$ analysed androstenedione capsules (listed on the label) and found that they also contained 19-nor-4-androstenedione (not listed on the label) in the range 4 - $18 \mu \mathrm{g} / \mathrm{capsule}^{1}$ Both in our study and that of
Catlin et al. ${ }^{1}$ the concentration of non-listed hormonal substances was in the $\mu \mathrm{g} / \mathrm{capsule}$ range. De Cock et al. ${ }^{3}$ found much higher concentrations of 4-androstenedione and 19nor-4-androstenedione $(0.7 \mathrm{mg}$ and $4.8 \mathrm{mg} /$ capsule respectively) in a nutritional supplement. These hormonal products were not listed on the label.

The stimulants were listed on the labels as Ma Huang, Guarana and Kola extracts (Table II). All 4 supplements contained a mixture of ephedrines and caffeine. The supplements contained ephedrines and caffeine in varying concentrations, with the ephedrine concentrations corresponding to those of cold and flu drugs (5 - $10 \mathrm{mg}$ ). The recorded caffeine concentrations were lower than those of a cup of coffee (90 - 150 mg caffeine).

When Ma Huang extract or herbal tea blend was listed on the label different ephedrines were detected in the supplements in different concentrations, as illustrated in Table II. Larimore and O'Mathúna ${ }^{7}$ found that ephedra products varied in ephedra alkaloid content, a finding similar to that in our study. The problem is that when Ma Huang extract is listed on the label as an ingredient of the supplement it does not warn the athlete that it contains banned substances. Supplement 2 listed herbal tea blend as one of the ingredients, with no indication that it contained ephedra. The fine print on the label of this supplement warns professional athletes not to use this product, but no clear reason for this is given.

Inadvertent doping can occur in three ways: $(i)$ prohibited substances are declared on the label but the athlete is not aware that it is a banned substance; (ii) prohibited substances are declared on the label, but under different names which the athlete is unfamiliar with (e.g. ephedrine is listed as Ma Huang, Chinese ephedra, epitonin, sida cordifolia, or ephedra, while caffeine is listed as Guarana, Kola or Gotu Kola); and (iii) prohibited substances are not declared on the label - these substances could have been added deliberately, or could be the result of contamination during or after synthesis, capsulation, or packaging.

The IOC and WADA have a clause of strict liability stating that the athlete is ultimately responsible for what is found in his/her body fluids irrespective of its origin. Therefore, the risk of an inadvertent positive test after using nutritional supplements remains the athlete's responsibility.

Supplements $5,6,7,14,22$, and 24 clearly stated on the label that they contained banned substances, in which case ignorance on the part of the athlete is no defence. Supplements 19 and 20 may fall into two different categories. The first category is what can be called 'contamination' - during the manufacturing process (using the same machines to produce non-hormonal and hormonal supplements) the product is unintentionally mixed with a very small amount of banned substance. Clearly there was no intent on the side of the supplement company, just a lack of quality control. The second category is 'mislabelling' whereby the supplement company intentionally adds small amounts of 
performance-enhancing steroid or stimulant compound to boost the effectiveness of a particular product. On its own the supplement may show no performance improvement. The practice of the supplement company in this instance is unethical. Although these two categories are different, the athlete still has to accept responsibility for a positive dope test as it is very difficult to prove the two scenarios from the side of the manufacturing company and what supplement was actually used by the athlete.

\section{Conclusion}

The results show that inadvertent doping through nutritional supplement use is a reality for athletes. The sporting community should therefore be aware that supplements might contain anabolic androgenic steroids and stimulants that are not declared on the labels.

\section{REFERENCES}

1. Catlin DH, Leder BZ, Ahrens B, et al. Trace contamination of over-thecounter androstenedione and positive urine test results for nandrolone metabolite. JAMA 2000; 284: 2618-21.

2. Cawley AT, Trout GJ, Kazlauskas R. Quantitation of urinary caffeine by GC/MS using 13C caffeine as internal standard. In: Schänzer W, Geyer H, Gotzman A, Mareck-Engelke U, eds. Proceedings of the 19th Cologne Workshop on Dope Analysis. Cologne: Sport und Buch Strausse, 2001: 229-32.

3. De Cock KJS, Delbeke FT, Van Eenoo P, Desmet N, Roels K, De Backer P. Detection and determination of anabolic steroids in nutritional supplements. J Pharm Biomed Anal 2002; 25: 843-52.

4. Geyer H, Henze MK, Mareck-Engelke U, Wagner A, Schrader $Y$, Schänzer W. Analysis of 'non-hormonal' nutritional supplements for prohormones. In: Schänzer W, Geyer H, Gotzman A, Mareck-Engelke U, eds. Proceedings of the 19th Cologne Workshop on Dope Analysis. Cologne: Sport und Buch Strausse, 2001:63-72.

5. Geyer H, Parr MK, Mareck U, Reinhart U, Schrader Y, Schänzer W. Analysis of non-hormonal nutritional supplements for anabolic androgenic steroids - Results of the International IOC study. In: Schänzer W, Geyer H, Gotzman A, Mareck-Engelke U, eds. Proceedings of the 20th Cologne Workshop on Dope Analysis. Cologne: Sport und Buch Strausse, 2002: 83-6.

6. Kamber M, Baume N, Saugy M, Rivier L. Nutritional supplements as a source for positive doping cases. International Journal of Sport Nutrition and Exercise Metabolism 2001; 11: 258-63.

7. Larimore $\mathrm{WL}, \mathrm{O}$ 'Mathúna. Quality assessment programs for dietary supplements. Ann Pharmacother 2003; 37: 893-898.

8. Van der Merwe PJ, Brown LW, Hendrikz SE. Simultaneous quantification of ephedrines in urine by high-performance liquid chromatography. $J$ Chromatogr B Biomed Sci Appl 1994; 661: 357-61.

Invited comment by Shelly Meltzer, Board Member of the SA Institute for Drug Free Sport, and Dietician, Sport Science Institute of South Africa, Cape Town.

Despite similar studies having been done overseas, ${ }^{1-3}$ the supplement industry (unlike food and drugs) is still uncontrolled and poorly regulated. There is generally no control on the production (i.e. no standard manufacturing practice), importation, distribution and marketing of supplements; there is no control on the exact composition of these products and there is no system to ensure that the products are safe and effective. The above study by van der Merwe and Grobbelaar is therefore very relevant and will hopefully bring home the message that supplements that are locally avail- able are indeed risky and that our athletes have no guarantee that they will not be ingesting contaminants, banned substances or by-products from the synthesis of pro-hormones or other banned substances when using supplements. Moreover, in accordance with international rules, athletes remain responsible for what is found in their body fluids, irrespective of the origin. This surely raises ethical questions for professionals who advise athletes to take these substances, knowing that should athletes test positive for banned substances they may be ineligible to compete, thus ruining their career.

Perhaps it is also important to clarify a few other misconceptions regarding sports supplements. Here are the facts:

1. Sports supplements are not any safer than vitamins and minerals.

2. Supplements marketed as 'natural' are not necessarily acceptable. Even herbals may have side-effects.

3. Presently there is no way to recommend with certainty that one particular brand is safer than another. Although some international institutions have introduced certification programmes for supplements there are still loopholes. Athletes are therefore advised to request the supplier of any supplement to provide a quality control certificate. This certificate should demonstrate that the product has been tested at an independent IOC-accredited laboratory and has been shown to be free of prohibited substances. Furthermore, the certificate should have legally binding documentation listing all the contents of all the different products that the company produces and a statement that the company accepts full liability should an athlete use the supplement and fail a drug test. This guarantee document should: (i) be on a company letterhead; (ii) be signed by management and dated; (iii) include contact details for the person responsible for issuing the guarantee; (iv) address the athlete directly by name, and not be addressed generally, e.g. 'To whom it may concern'.

4. Even if the product label says 'IOC permitted' this does not mean it is safe to use. The IOC does not endorse any nutritional supplements.

5. The USA Food and Drug Administration (FDA) has notified manufacturers of its intent to ban the sale of dietary supplements containing ephedrine alkaloids. However, there may still be athletes with stocks of supplements that contain ephedrine which may be listed on the label under various pseudonyms (refer to the study) or in some products may not have been declared. Products do not always contain what is listed on the label. Batch-to-batch differences in nutrients may vary considerably in one brand and there have been reports of supplements containing dangerously high (e.g. niacin) and low (e.g. folic acid) levels of nutrients. You may even get more than what you have paid for. The FDA reports that upon inspection supplements have been found to contain aflatoxin, mycotoxin, lead, salmonella and even glass (http://www.fda.gov/dockets/ecomments.).

6. Even small amounts of a contaminant (e.g. 0.02\% nandrolone in a supplement) may cause a positive test. 
7. Although caffeine has recently been removed from the banned IOC/WADA lists it is still advisable to be familiar with the wide range of caffeine-containing foods, beverages (e.g. energy drinks, sports drinks, tea and coffee), sports gels and drugs to avoid any undesirable side-effects which may negatively affect performance.

8. Products often make false claims.

A practical guide describing the efficacy and use of nutritional supplements in sport has been compiled for SA Rugby and is available from the South African Institute of Drug Free
Sport (www.drugfreesport.org.za)

\section{RefERENCES}

1. Catlin DH, Leder BZ, Ahrens B, et al. Trace contamination of over-thecounter androstenedione and positive urine test results for nandrolone metabolite. $\mathcal{F A M A}$ 2000, 284:2618-21.

2. Geyer H, Mareck-Engelke U, Reinhart U, Schänzer W. Positive dope control cases with norandrosterone after application of contaminated nutritional supplements. D Zeitschr Sportmed 2000, 51: 378-82.

3. Kamber M, Baume N, Saugy M, Rivier L. Nutritional supplements as a source for positive doping cases? International fournal of Sport Nutrition and Exercise Metabolism 2001; 11: 258-63. 